\title{
The Rise of Industrial East Asia: The Role of Confucian Values
}

TU WEI-MING

The study of East Asia as an intriguing Problematik in the field of economic development and as a methodological challenge in comparative politics has fascinated academicians in North America and in Western Europe for a whole generation. Only recently has it become a major concern of policy makers and the general public in the so-called First World. Ironically, as government officials and the mass media begin to show great interest in the rise of industrial East Asia, cautious academicians feel compelled to make more differentiated observations about the region. As a result, the public demand for broad generalizations is often met with considerable qualifications from the academic community. Indeed, scholarly efforts have been made to show that the whole concept, "Industrial East Asia," may be inadvisable, that Japan is an anomaly on the world economic stage and that the rise of these states as the most dynamic region in international trade has very little to do with shared cultural orientations.

As a student of East Asian culture, I am excited that interpreting East Asia in the light of conceptual resources learned from the West, originally the professional goal of a small coterie of like-minded researchers, is now shared by a widening network of concerned citizens of the world. I am also grateful that fascination with Japan and the Four "Mini-Dragons" has progressed from exclusively economic and political analyses to include social studies and cultural appreciation. I use the word "progressed" advisedly. Even though I emphasize the vital importance of culture in our understanding of East Asia, I am fully cognizant of factors such as international trade, the geopolitical situation and the institutional sector in formulating an explanation for the rise of industrial East Asia.

\section{The Sinic World and The Confucian Challenge}

The recent Western fascination with East Asia began with a hard economic reality; the challenge from Japan's and the Four Mini-Dragons' manufacturing industries and financial enterprises is clearly threatening Western supremacy. Since economic reality, in this case the competitive edge, is 
often the function of the political infrastructure which enables domestic entrepreneurship to flourish and export-oriented trade policies to work, investigation of those key institutions responsible for economic dynamism, such as the MITI in Japan, ${ }^{1}$ seems to be a logical step. Social studies and cultural appreciation are more difficult to justify purely in economic terms. The whole area of research generically characterized as "economic culture" is still in a nascent phase, despite Max Weber's classical study on the Protestant Ethic and the Spirit of Capitalism. Indeed, the need to understand the dynamics of East Asian societies and to appreciate their cultural values may be motivated by an impulse wholly different from the desire to find an explanation for their economic competitiveness. Nevertheless, the move from economic and political analyses to social studies and cultural appreciation does signify "progress." For one thing, the conventional rhetoric of dismissing Japan as an "anomaly" or as a mere "imitator" of the United States is no longer persuasive. The willingness to confront the "economic miracle" of Japan not merely as a temporary event but as an enduring form of life seems to be widespread in the minds of the American educated public. ${ }^{2}$

Actually, the arrival of the vigorous newcomers, Hong Kong, Singapore, Taiwan and South Korea, with a sustained average annual growth rate at $10 \%$ since the 1970 s impels us to look at the Japanese case in a new cultural context. $^{3}$

When Professor Reischauer offered his insightful observations on "The Sinic World in Perspective" to the Conference on the "Dynamics of Northeast Asia," arranged by the Asia Society in Japan in November $1973,{ }^{4}$ he was sharing a common-sense observation about East Asian cultural history with his primarily Europe-centered colleagues. The brilliance of Reischauer's presentation lies not only in its clear and balanced view but also in its predicative power. In fact, he implicitly urged policy makers and opinion leaders to look at East Asia as a cultural system. Despite its diversity, this cultural system follows rules of the game significantly different from those taken for granted in the West. Unless we understand and appreciate what sort of values underlies their game, we will continue to misinterpret what they do in terms of our rules without any knowledge that their game, while intersecting with ours, is much more complex than ours. The message that Reischauer intended to convey is simply: take the role of culture, specifically Confucian values, seriously in approaching East Asia: 
The basic ethical concepts and value systems of the four countries [China, Japan, Korea and Vietnam] are surprisingly uniform.

For example, all show a strong emphasis on family solidarity, on filial piety, on subordination of the individual to the group, on the ideal of group harmony as opposed to a balance between conflicting rights, on social organization, on careful political (as opposed to religious or purely culture) integration, on hard work as a value in itself, on frugality, and on education as morally uplifting and as the proper road to personal and family success, though the Japanese have added to these values a special emphasis on stoicism, martial virtues, and extra-family loyalities derived from their feudal experience. Seen in such basic terms, East Asia has been in the past and still is in many ways every bit as much of a cultural unit as is the West.

Paradoxically what Reischauer offered as common sensical turned out to be an inscrutable puzzle: a box within a box, multiplicity in simplicity, and unity in diversity, a point I will elaborate on later.

The futurologist, Herman Kahn, speculated in the late 1970s that the rise of East Asia would have profound implications for the West, in particular, for the United States. ${ }^{5}$ In specifying the ethico-religious background that prompted the re-emergence of this region as a major challenge to the American way of life, Kahn identified Confucian morality as the functional equivalent of the Protestant Ethic and as the cultural base of the rise of industrial East Asia. Despite his journalistic penchant for anecdotal evidence, Kahn's bold assertion that the age of Pax Americana would be seriously challenged by the Pacific region foreshadowed much of the current discussion on the wealth and power of the Pacific Rim. Kahn's decision to focus his attention on the role of culture, more of an intuitive feeling than an informed judgment at the time, is fully supported by Roderick MacFarquhar's influential article in the Economist in February 1980. His notion that the Western dominance of the world since the onset of the industrial revolution two centuries ago is threatened in a more fundamental way by "the East Asian heirs to Confucianism" than by either the Russians or the Arabs underscores Kahn's hypothesis that, due to the strength of "neo-Confucian cultures," under current conditions, "Japan, South Korea, Taiwan, Hong Kong, Singapore, and the ethnic Chinese minorities in Malaysia and Thailand seem more adept at industrialization than the West"; accord- 
ingly, the Confucian ethic "will result in all the neo-Confucian societies having at least potentially higher growth rates than other cultures."

A caveat needs to be noted at this juncture. The prediction of the "decline of the West" since Spengler and the fear of a re-awakening of China as a "Yellow Peril" since Napoleon have been recurring themes (nightmares!) in the post-Enlightenment intellectual consciousness in the modern West. The dynamics of modern West, characterized not only by military might and industrial strength but also by the vibrant market, the emergence of "civil society," the creation of new values, and conscientious institutionbuilding at all political and social levels, has always been a mixed blessing pregnant with perilous self-destruction as well as great potential. Toynbee's concern for the decline of Christendom and Solzhenitsyn's anxiety over the disintegration of the moral fabric of American society are twentieth-century examples of this critical self-consciousness in the modern West. A major factor lurking behind the scene is of course the great uncertainty about what China, indeed the Sinic world, would become. While I strongly disapprove of the employment of an implicit social Darwinian method in perceiving the rise of industrial East Asia as a threat to the "fitness" of the western mode of life, I am fully aware of the implications of our discussion for the public mind. I mention this in passing as a caveat with the hope that my European audience will be on the alert against misinterpreting the rise of industrial East Asia as a mere exercise in competitive survivability. For I believe that self-reflexivity among concerned intellectuals in the modern West is a precondition for putting the question of Japan and the Mini-Dragons in a global perspective. For decades, indeed generations, a defining characteristic of the role and function of intellectuals in East Asian societies has been to bring understanding of the modern West to concerned citizens of their countries. However, the modern West as a phase of human civilization (by now an inextricable dimension of our common heritage in the "global village") urgently requires enlightened reexamination.

\section{The Weberian Thesis and Western Individualism}

Reischauer, Kahn and MacFarquhar, by linking Sinic culture, particularly Confucian ethics, to East Asian economic productivity, pose a serious challenge to the commonly understood Weberian thesis that, despite 
favorable conditions for rationalization in traditional China, Confucian humanism, as opposed to Protestant Calvinism, was inimical to the development of the spirit of capitalism.

This is not the place to reexamine the Weberian thesis, but it is worth noting that in the current discussion on the rise of industrial East Asia Weber's classical interpretation of the relationship between a particular life-orientation and the economic ethics necessary for the development of the spirit of capitalism serves well as a point of departure.

The attempt to characterize the Confucian ethic as the functional equivalent of the Protestant ethic in industrial East Asia is, however, seriously flawed. Weber's thought- provoking analysis is culturally and historically specific.

The spirit of capitalism, as the unintended consequence of the work ethic inspired by Calvinism, once kindled, tended to engulf the world with its own momentum and inner logic. The dynamism of the modern West, fired by the Faustian drive to explore, to know and to conquer, is an ambivalent heritage. It is both an "enlightenment," a triumph of human rationality and, in Weber's prophetic words, an "iron cage." Weber may have underestimated the creative tension engendered in the Confucian personality $^{8}$ (Thomas Metzger has successfully refuted the Weberian assertion that the paradigmatic Confucian takes adjustment to the world as his way of life), ${ }^{9}$ but his observation that the motivating force, generated by a powerful anxiety in loneliness, compelling the Puritan to fashion the outside world in a premeditated and calculated way is absent in the Confucian life orientation is still pertinent. The problem with the facile attempt to label the Confucian ethic as the functional equivalent of the Protestant ethic is twofold: to abstract the Protestant ethic from its richly textured cultural and historical milieu to become a causal factor and to reduce the Confucian ethic to an instrumental value. The former is a gross simplification of the Weberian thesis and the latter is a total misreading of the role of Confucian values in the rise of industrial East Asia.

However, there is a measure of truth in interpreting the function of the Confucian ethic in industrial East Asia in terms of the function of the Protestant ethic in the modern West. For one thing, the development of "classical" capitalism in the Protestant West is the only frame of reference in which the development of "modern" capitalism in Confucian East Asia is to be understood. Whether or not we accept Peter Berger's characterization of East Asian capitalism as the "second case" because it is "non- in- 
vidualistic," his argument that "the development of modernity in the West suggests a reciprocal relationship with individualism" merits our special attention:

Western civilization generated a distinctive individualism that was very congenial to modernity; in turn, the process of modernization greatly accentuated this individualism, and, one may add, successfully exported individualism to other parts of the world. Not surprisingly, various theorists of modernization (for instance, Talcott Parsons) assumed that individualism (or, as he called it, "ego-orientation") is inevitably and intrinsically linked to modernity. ${ }^{10}$

Needless to say, individualism underlies the Weberian conception of the Protestant ethic. A salient feature of the Puritan who became a master in the pursuit of rational self-interest and in the maximization of profit is "ego-orientation." Berger's argument that "the Western individualism provided a fertile soil for the birth of a number of important elements of modernity such as, for an important example, the birth of the capitalist entrepreneur" ${ }^{\prime 11}$ is highly plausible. This partly explains why Weber and those under the influence of Weber's persuasive power failed to see the transformative potential in Confucianism: an ethic that perceives the self as a center of relationships, advocates social harmony and demands communal participation is merely "adjustment to the world." Berger further noted that "as modernity came into being [in the West], it dissolved older, more collectively oriented communities and institutions, throwing the individual much more on himself, and thus fostering both the values and the social- psychological reality of individualism." ${ }^{12}$ This shift from Gemeinschaft to Gesellschaft (Ferdinand Tönnies) and from "mechanical solidarity" to "organic solidarity" (Emile Durkheim) in much of classical sociological thought enabled Berger to establish the link between individualism and modernity noted earlier. ${ }^{13}$

By contrast, Berger's "second case" of capitalist modernity or the "East Asian model" is predicated on the assumption that the rise of industrial East Asia, as a form of modernization, has not been associated with individualism. Moreover, he hypothesizes that "a key variable in explaining the economic performance of these countries is Confucian ethics - or postConfucian ethics, in the sense that the moral values in question are now 
relatively detached from the Confucian tradition proper and have become more widely diffused." ${ }^{14}$ Underlying this line of thinking is the belief that communalism rather than individualism or "group-orientation" rather than "ego- orientation" is the hallmark of East Asian modernity. If this is the general picture, the question of what kind of name ("bourgeois Confucianism," "vulgar Confucianism," or "popular Confucianism") is most appropriate to describe such an ethics becomes less urgent.

\section{Confucian Values and East Asian Modernization}

Paradoxically scholarship on modernization in East Asia has since the late 1950s assumed that it was precisely because Confucianism is inevitably and intrinsically linked to communalism and "group-orientation" that it incompatible with modernity. Put in a more ideologically motivated parlance in Marxist historiography in the People's Republic of China, since Confucianism is "feudalistic," it is incompatible with either the capitalist or the socialist phase of modernization. Understandably, it has been widely held that, aside from clearly identifiable institutional reasons, Confucian ethics with its emphasis on traditional communities rather than innovative individuals, is the main reason for East Asian backwardness.

Specifically, the Confucian concern for self-cultivation, family cohesiveness, social stability, and government leadership is labelled "traditionalist" because it is in sharp contrast with the "modern" demand for self-interest, voluntary association, social change, and the adversary system based on competing claims on power and resources. ${ }^{15}$

If we broaden Berger's focused investigation of individualism, which seems to single out the entrepreneurial spirit in the free market as the single most important motive force in the modern West, we may want to consider a variety of other factors underlying the impressive demonstration of "instrumental rationality," such as the growth of governmental bureaucracy, the emergence of the university (or the multiversity) and the development of the civil society. It was not only individual-centered activity but also the new social and political structures developing out of collective human ingenuity that made the modern. West dynamic. If we are willing to entertain a more differentiated and sophisticated view of the modern West even at this level of macro-analysis, we must disaggregate the complex modernizing Western experience according to the specific condi- 
tions of its major architects: Great Britain, France, the United States and a host of other countries. The sharp contrast between Confucian humanism and Western modernism, as a result, will dim in some cases. The role of tradition in Great Britain, the pervasiveness of bureaucracy in France, the centrality of national identity in Germany and the concern for public morality in the United States are obvious examples.

Actually, persuasive voices about the relevance of Confucian humanism to the industrial development of East Asia were heard in the modernist age, the period when theorists of modernization dominated social scientific thinking in the United States (from the late 1950s to the early 1970s). While hindsight may impel us to wish for a more nuanced and subtle treatment of Confucian values in modernity, their considerable effort in putting the Confucian question on the agenda is, in itself, a significant contribution to our current discussion. Let me briefly mention only three East Asian scholars. Masao Maruyama's classical study of modern Japanese political thought underscores the importance of a critical transformation in Confucian symbolism as the precursor of Japanese modernity. His emphasis on the pivotal role of Ogyu Sorai may appear to be one-sided in light of: recent scholarship on the Tokugawa period, but the agenda he set up for understanding the Japanese mind from a modernist perspective has helped shape contemporary Japanese Confucian studies. ${ }^{16}$ Robert Bellah's Tokugawa Religion, a seminal essay on Japan's ability to tap into her premodern spiritual life resources for modern transformation, ${ }^{17}$ may not have been directly indebted to Maruyama, but demonstrates the sugges tiveness of Maruyama's mode of questioning. Lee Sang-eun's concerted effort to bring Confucian ethics into the contemporary discourse on Korean modernization is less well-known. Yet, as an exemplary teacher, an actionintellectual and a scholar-thinker he became a source of inspiration for those who were both involved in Confucian studies and intensely concerned with Korea's modernization. ${ }^{18}$ Similarly, T'ang Chun-i and his colleagues at New Asia College in Hong Kong and Tunghai University in Taiwan led a cultural movement to transform Confucian humanism into modern world view without losing sight of its spiritual identity. ${ }^{19}$ Without their indefatigable commitment to the Confucian course, Levenson's fear for the museumization of the Confucian heritage might have already become a reality. ${ }^{20}$

Notwithstanding the significant works just mentioned, the general impression that Confucian values are incompatible with and detrimental to 
East Asian modernization persisted in the scholarly community throughout the world. The modernist critique of Confucian humanism was so widely shared by historians, economists, sociologists, political scientists, and anthropologists that those who cherished the thought that Confucian values are relevant to and beneficial for East Asian modernization appeared defensive, apologetic and outright irrational.

\section{Industrial East Asia as the Confucian Model of Modernization}

We now readily see the limitation of the conceptual scheme defining modernization in terms of Western exceptionalism. We are aware that the genetic conditions that made the modern West the paradigm of human efflorescence are significantly different from the structural reasons necessary for developing industrial capitalism and liberal democracy. In other words, the dynamism of the modern West may have become the envy of the rest of the world, but its cultural specificity makes it in a substantial way non-exportable. To be sure, much of what the modern West exemplifies provides standards of inspiration for the rest of the world. Arguably it will continue to provide heuristic models for East Asia for decades to come. After all, most of the spheres of interest defining modern economy, polity, society and culture are of Western origin. Even the conceptual apparatuses used throughout the world to study and appreciate them are indelibly Western. East Asian intellectuals are acutely aware of their indebtedness to the Western modes of thinking. Often they have more intimate knowledge of the life worlds of the modern West than the spiritual realms of their own cultural traditions.

Nevertheless, it is undeniable that something essential in shaping our modern consciousness has happened since the end of the Second World War and begun to come into view in the 1970s. Although we are still at loss clearly to define what the shape of the beast really is, we have enough indications to know that it is new and that existing conceptual apparatuses are quite inadequate to perform the task of describing it. The rise of industrial East Asia must be perceived in this new light. The reassessment of the role of Confucian values is occasioned by this consideration.

To recapitulate the process by which Reischauer, Kahn and MacFarquhar alerted us to the cultural significance of the rise of industrial Asia, the isomorphic features of Japan and the Four Mini-Dragons in the modern- 
izing process actually compelled them to take seriously the role of Confucian values. Put differently, the role of Confucian values in these societies enabled them to group Japan and the Four Mini-Dragons as members of the same cultural system. For anyone familiar with East Asian history, this is indeed a common-sense observation. However, since the modernist explanatory model, thoroughly conditioned by the unique Western developmental experience despite great regional varieties, tends to undermine precisely the isomorphic features these societies share as their Confucian heritage, the common-sense observation becomes painfully difficult to defend: it can either be brushed aside as an unexamined Sinic bias or perfunctorily accepted as a truism which does not merit any critical reflection.

It is now generally acknowledged that despite diversity in size, population base, ethnic composition, colonial experience, degree of Westernization, political system, social structure and stage of economic development in industrial East Asia, these states share a common cultural heritage which notably includes Confucian ethics. The intriguing issue is the way Confucian ethics has permeated these societies. A corollary may be the extent to which Confucian ethics is embedded in the social practice and political culture of Japan and the Four Mini-Dragons. The observation of the Singaporean economist, Tan Kong Yam, is pertinent here:

The Confucian emphasis on government leadership, filial piety (both within the family and at the national level), social discipline and harmony have created political institutions in East Asia that are quite distinct from that of the Euro-American tradition. Unlike the Euro-American model which traces its origin to the liberal tradition of Adam Smith (and with its modern manifestation in Reaganism and Thatcherism) which treats government as a necessary evil and should be confined to only law and order, the Confucian values and tradition lead to a model of maximal government, with its myriad responsibilities, duties and obligations. The State is not just supervisory and regulatory in function but to a very large extent developmental, educational and mobilizational in emphasis. The bureaucracy is not just administrative and government functionaries but acts as guidance of national interests and is often perceived as leaders, intellectuals and teachers. As such, the recruitment pattern of leaderships in politics and civil service has been rather different in East Asian countries. Conflicts also tend to 
be personally or factionally based rather than issues or ideologically based .... ${ }^{21}$

Further comparative analysis would probably point out dimensions in modern Western political culture that are more compatible with Confucian ethics, but the host of Confucian values that is deemed conducive to economic development suggests a pattern of communicative rationality distinctively East Asian: faith in the transformability and perfectibility of the human condition, self as a center of relationships, the importance of selfcultivation, the desirability of hard work as social discipline, duty-consciousness, the centrality of the family in social harmony, the primacy of education, the political order as a moral community, the necessity of government leadership, the aversion against self-centeredness and the disinclination for civil litigation.

We need to remind ourselves that many of the Confucian values that have been identified as conducive to or instrumental in East Asian economic development recently were considered detrimental to or incompatible with East Asian modernization two decades ago. The same values that were thought to have hampered East Asian efforts to modernize (understood as Westernize at the time) are now singled out as the motivating forces that have empowered East Asian societies to prevail over their Western competitors. An easy explanation is that these shared values have blossomed into dynamic forces for development under the conducive environment created by innovative institutional settings. To be sure, "the opening of the Japanese and the NIEs' economies to the outside world and their subsequent subjection to rigorous competitive pressure of the international market economy, have undeniably contributed to their economic dynamism."22 It is also conceivable that in the current economic culture, the group- oriented new capitalism is more competitive than the individual-oriented classical capitalism. As a result, the Confucian values that had inhibited East Asian economic development in the early stage have now become efficacious in the later stage.

This assumption that values have been around more or less as a constant is problematical. Since values are embodied in concrete human beings who consciously respond to changing situations, they undergo a transformation which is often inadvertent but sometimes deliberate. The communal critical self-awareness of the East Asian intelligentsia seasoned in Confucian humanism has undergone major metamorphoses since the 
impact of the West in the mid-nineteenth century. The self-reflexivity of Chinese, Japanese and Korean intellectuals in absorbing the series of shocks occasioned by the Western encroachment plays a major role in shaping and reshaping Confucian values (including the iconoclastic rejection of the whole tradition) as a way of renewing their own sense of cultural identity. A brief encounter with East Asian history since the Opium War of 1839 should make it abundantly clear that the quests for the best way to imitate, learn, digest and internalize the Western form of life have generated many convulsive changes in the East Asian consciousness. The Confucian values that are thought to have helped East Asian economic development have themselves survived numerous assaults. However, they are very different from those that never confronted the ruthless questioning of radical otherness. For example, harmony achieved in a highly competitive pluralistic modern society is very different from harmony assumed in an undifferentiated farming community. The language of harmony in this case signifies a dynamic, evolving linguistic universe in which the Western grammar of action often functions as an active shaper of the rules of the game. It is worth noting that the Confucian values in contemporary East Asia are persuasive partly because thay have internalized, if not totally domesticated, a great deal of modern Western Enlightenment mentality. The Confucian value, such as harmony, that has conscientiously responded to the challenge of conflict defined in social Darwinian terms is a highly charged value. It is no longer the harmony that Weber characterized as "adjustment to the world." Rather, it is the result of conflict resolution, an attainment through delicate negotiation.

\section{Implications and Paradoxes}

If the rise of industrial East Asia symbolizes the realization of a Confucian model of modernization, a model built upon a deliberate appropriation of Western ideas and practices, the explanatory strategy predicated on the exclusive dichotomy of tradition and modernity is no longer workable. The hypothesis that modernization inevitably leads to the passing of traditional societies needs to be substantially revised. The unexpected vitality of Confucian values, such as familism, in Japan and in the Four Mini-Dragons strongly suggests that exploration of traditions in modernity is of crucial importance.

The interplay between primordial ties ingrained in specific traditions 
and global concerns transcending national boundaries makes the Confucian commitment to cultural embeddedness as a point of departure for inclusive humanism an appealing alternative to abstract universalism. As Edward F. Hartfield, an astute observer of "the divergent economic development of China and Japan," notes:

The most outstanding feature of the modernization experience of Japan and East Asia's other Confucian societies is the acceptance of culture as a significant force shaping a human-oriented workforce in the service of industrialization. That may be the most important legacy of Confucianism for modern times. ${ }^{23}$

As evidence supporting the Confucian hypothesis ("a key variable in explaining the economic performance of Japan and the Four Mini-Dragons is Confucian ethics" $)^{24}$ continues to come in, the authentic possibility of an East Asian development model impels us to accept the proposition that modernization can and must assume different cultural forms. The lesson we learn from this awareness is that the path to modernity, far from being a quest for uniformity (i.e. the "melting pot" as a form of abstract universality), always negotiates between deep-rooted cultural demands and new requirements dictated by the increasingly interdependent "global village."

If a regulated economy does not necessarily undermine the vitality of the market, if exemplary leadership is compatible with participatory democracy and if a grouporiented society can sustain its dynamism without recource to the adversary system governed by law, the Confucian model of modernization indicates a way of developing a stable economy, a humane government and a harmonized society pertinent to Communist Asia, namely China, North Korea and Vietnam, as well as industrial East Asia. Ironically, many of the culturally embedded structures that are thought to be efficacious in modernizing industrial East Asia are at the same time condemned as factors inhibiting the Chinese Mainland in her quest for reform. These include the omnipresence of the central government, the centrality of the family and the grouporientation in virtually all. social organizations. However, there is a world of difference between a Stalinist state which, taking the infallibility of the party for granted, develops an elaborate technique of total control and the Confucian idea of the benevolent government which assumes full responsibility for the well-being of the people. The governments in industrial East Asia are by no 
means "benevolent," but, to the extent that they are seasoned in Confucian culture, their sense of duty compels them to be publicly accountable; they are indeed a far cry from the self-righteous Stalinist dictatorship. The transformation from the Stalinist dictatorship to a style of powerful and accountable leadership reminiscent of the Confucian benevolent government will probably help the Chinese Communist Party to achieve its reformist goals, but the advocacy of "new authoritarianism" as a strategic move of the ruling minority is unlikely to work. For one thing, the Singaporean model could not be transferred to the Chinese political situation unless the Chinese Communist leadership substantially transcended its familism (i.e. nepotism). This seems unlikely given the rigid hierarchic political machinery designed for the primary purpose of staying in power.

To be sure, familism looms large in the economic and political cultures of industrial East Asia. As many scholars have observed, family networks, as essential features of the political landscape in Japan and the Four MiniDragons, have been instrumental in bringing about dynamism and harmony in capital formation, management and labor relationships. Familism as nepotism in the Chinese Mainland, by contrast, is totally antithetical to either entrepreneurial spirit or political accountability. As a dependent variable of the Stalinist state, nepotism as practiced by the ruling minority has become a monopolistic access to wealth and power. It is "feudalism" at its worst; if genetically such a "feudal" practice has its roots in Confucianism, it is the kind of Confucianism that has lost much of its persuasive power in industrial East Asia. Of course it would be naive to believe that since politicians in East Asia (notably in Taiwan, South Korea and Singapore) have consciously tried to appropriate Confucian values in their styles of rulership, they have in practice realized the ideas of the "benevolent government." However, undeniably, since Confucian ethics have been cultivated in these societies, it has become a legitimate indigenous resource for the governmental and societal leadership to tap from. Actually, Confucian ethics is so much an integral part of moral education in these societies that it has become the grammar underlying the common discourse on civilized conduct. On the contrary, in Mainland China Confucian ethics remains "habits of the heart" which often serve to justify nepotistic behavior.

In conclusion, let me make brief references to two paradoxes and a promise in addressing the role of Confucian values in the rise of industrial East Asia. In painting "a political portrait" for "the New Asian Capital- 
ism," Lucian Pye perceptively describes the "Confucian paradox" as follows:

[T] he East Asian countries that are now having such striking economic successes shared a Confucian heritage which was traditionally scornful of merchants and materialistic accomplishments. Conventional wisdom has long held that Confucianism was a drag on economic development. Yet, today we find that other countries in Asia with different cultural roots are finding it difficult to emulate the East Asian economic model, precisely because they lack those qualities inherent in that Confucian legacy. ${ }^{25}$

Another paradox, equally intriguing, is the contrasting economic performances of industrial East Asia and communist East Asia. Both, presumably, are inheritors of the Confucian legacy. The interaction between Confucian humanism and Marxism-Leninism on the one hand and between Confucian humanism and Liberal Democratic ideas on the other may shed some light on this obvious divergence. The difficulty confronting the Chinese Mainland on the ideological front is complicated by the vaguely perceived but deeply felt struggle between Socialism and Capitalism. A hopeful sign is the possibility of a narrow ridge between Confucian humanism and Liberal Democratic ideas in the socialist context. In this connection, an inquiry into the relationship between Confucian humanism and democracy is absolutely necessary for us to understand the dynamics of East Asia not only as an economic reality but also as a form of life.

The form of life characterized by Confucian ethics is significantly different from the distinctively modern Western Enlightenment mentality. The host of values derived from the French Revolution, notably liberty, equality, fraternity, human rights and rule of the law, are now universal aspirations. Confucian ethics with its emphasis on humanity, rightness, propriety, wisdom, filial piety and loyalty may appear to be in a fundamental disagreement with the Enlightenment values. ${ }^{26}$ However, in a deeper sense, the tension between liberty and equality, the difficulty of realizing fraternity in an adversary system defined in term of competing rights and the intrusiveness of litigation in the private life of the citizen may prompt the Enlightenment mentality to appreciate the Confucian emphasis on the fiduciary community. Similarly, the abusive application of Confucian duty-consciousness by the ruling minority to ensure obedience without recourse to freedom of speech and an independent judicial system forces 
Confucian humanists to critically examine the negative social consequences of filial piety and loyalty. Even though incommensurability is widely acknowledged between Confucian and Enlightenment values, the great promise of a genuine dialogue lies in the newly emergent communal critical self-awareness among Europeanists and the East Asianists in the intellectual community.

Tu Wei-ming is Professor of Chinese History and Philosophy and Chairman of the Dept. of Asian Languages and Civilisations, Harvard University.

\section{NOTES}

1 Chalmers Johnson, MITI and the Japanese Miracle (Stanford: Stanford University Press, 1982).

2 For a pioneering account of the rise of Japan as an economic superpower see Ezra Vogel, Japan as Number One (Cambridge, Mass.: Harvard University Press, 1979).

3 See, for example, Roy Hofheinz and Kent E. Calder, The Eastasia Edge (New York: Basic Books, 1982).

4 Edwin O. Reischauer, "The Sinic World in Perspective," Foreign Affairs (January 1974), pp. 341-348.

5 Herman Kahn, World Economic Development (Boulder, Colorado: Westview Press, 1979).

6 Herman Kahn, World Economic Development, pp. 118, 122. It should be noted that Kahn's use of the term "neo-Confucian" is misleading. Obviously, he has the modern transformation of Confucian humanism in mind. The term "New Confucian" or "Post-Confucian" seems more appropriate.

7 Max Weber, The Protestant Ethic and the Spirit of Capitalism, transl. from German by Talcott Parsons (London: George Allen \& Unwin, 1930).

8 For Weber's general discussion on Confucianism, see his The Religion of China: Confucianism and Taoism ${ }^{7}$, transl. from German by Hans H. Gerth (Glen- coe, Illinois: Free Press, 1951). For a recent reexamination of the Weberian interpretive stance on Chinese religion, see Wolfgang Schluchter, ed., Max Webers Studien über Konfuzianismus und Taoismus (Frankfurt: Suhrkamp, 1983).

9 Thomas Metzger, Escape from Predicament and China's Evolving Political Culture (New York: Columbia University Press, 1977).

10 Peter L. Berger, "An East Asian Development Model?," in Peter L. Berger and Hsin-huang Michael Hsiao, eds., In Search of an East Asian Development Model (New Brunswick, New Jersey: Transaction Books, 1988), p. 6.

11 Ibid., p. 5.

12 Ibid., p. 5.

13 Ibid., pp. 5-6.

14 Ibid., p. 7.

15 For an overview of a current debate on this issue in Chinese, see Du Nianzhong and Yang Junshi, eds., Rujtalunli yu jingji fazhan (Confucian ethics and economic development) (Taipei, Yunchen, 1988).

16 Masao Maruyanıa, Nihon seiji shisoshi kenkyu (A study of political thought in Japan) (Tokyo: University of Tokyo Press, 1952). For a collaborative effort to study the Tokugawa period in the United States, see Peter Nosco, ed., Confucianism and Tokugawa Culture 
(Princeton: Princeton University Press, 1984). See also Tetsuo Najita and Irwin Scheiner, eds., Japanese Thought in the Tokugawa Period (Chicago: University of Chicago Press, 1978).

17 Robert N. Bellah, Tokugawa Religion (Glencoe, Illinois: Free Press, 1957).

18 See the Report on the International Conference on the Problems of Modernization in Asia, edited by the Editorial Committee chaired by Lee Sang-eun (Seoul: Asiatic Research Center, Korea University).

19 See, for example, T'ang Chun-i's paper contributed to the Conference organized by Professor Lee mentioned in note 18, "The Reconstruction of Confucianism and the Modernization of Asian Countries," in Intemational Conference on the Problems of Modernization in Asia, pp. 101-103.

20 See Joseph Levenson, Confucian China and Its Modern Fate: A Trilogy (Berkeley: University of California Press, 1968).
21 Tan Kong Yam, "Pattern of Asia Pacific Economic Growt th and Implications for China," pp. 11-12. Paper presented at the Symposium on Economic and Trade Cooperation between China and Asian Pacific Region, Beijing, October 28-31, 1989.

22 Ibid., p. 11.

23 Edward F. Hartfield, "The Divergent Economic Development of China and Japan," in Hung-chao Tai, ed., Confucianism and Economic Development: An Oriental Alternative? (Washington, D.C.: The Washington Institute Press, 1989), p. 110.

24 Peter Berger, "An East Asian Development Model?," p. 7.

25 Lucian Pye, "The New Asian Capitalism: A Political Portrait," in In Search of an East Asian Development Model, p. 86.

26 For a preliminary exploration of this issue, see Tu Wei-ming, "The Enlightenment Mentality and the Chinese Intellectual Dilemma," paper presented to The Four Anniversaries Conference, Annapolis, Maryland, September 11-14, 1989. 